

\title{
Heat Transfer Prediction of In-Service Welding In a Forced Flow of Fluid
}

\section{PER LINDSTRÖM}

Department of Shipping and Marine Technology CHALMERS UNIVERSITY OF TECHNOLOGY Göteborg, Sweden 2005 
THESIS FOR THE DEGREE OF LICENTIATE OF ENGINEERING

\title{
Heat Transfer Prediction of In-Service Welding In a Forced Flow of Fluid
}

\author{
PER LINDSTRÖM
}

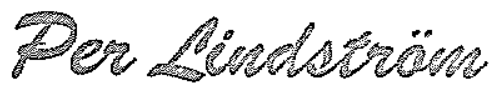

Bäcksiänten 3

SE-451 32 Uddevalla

Tel. $+46(0) 52218097$

Department of Shipping and Marine Technology CHALMERS UNIVERSITY OF TECHNOLOGY

SE-412 96 Göteborg, Sweden, 2005 
Heat Transfer Prediction of In-Service Welding In a Forced Flow of Fluid PER LINDSTRÖM

\section{Copyright $\odot 2005$ PER LINDSTRÖM}

Permission is granted to copy, distribute and/or modify this document under the terms of the GNU Free Documentation License, Version 1.2 or any later version published by the Free Software Foundation; with no Invariant Sections, no Front-Cover Texts, and no Back-Cover Texts. A copy of the license is included in the section entitled "GNU Free Documentation License".

ISSN 1101-0614

\section{R-05:91}

Department of Shipping and Marine Technology

Chalmers University of Technology

SE-412 96 Göteborg

Sweden

Telephone: $+46(0) 317721000$

Web: www.na.chalmers.se

Printed by:

Reproservice, Chalmers University of Technology

Göteborg 2005 


\begin{abstract}
Heat Transfer Prediction of In-Service Welding In a Forced Flow of Fluid

PER LINDSTRÖM

Department of Shipping and Marine Technology

Chalmers University of Technology

An algorithm to estimate the cooling rate of welding seams on the shell plating of a ship, below the waterline and during voyage has been derived. The algorithm derived is also applicable for welding on pipes and tubes containing a forced flow of fluid, so called inservice welding. The demand for this technique has arisen from the request of ship and process plant operators to make it possible for the safe repairs of their precious structures without taking them out of operation. The strength of the shell plating after welding is determined by its metallurgic structure, which is dependent on the cooling rate, its chemical composition and the original grain size of the base material. The cooling rate for this type of welding seam depends on the thickness of the plate, the velocity of the fluid, and the heat from the heat-input of the welding process.

The algorithm presented is derived from Rosenthal's 3D heat flow equation and boundary layer approximations. This has been possible by the introduction of an apparent thermal conductivity, $\mathrm{k}_{\mathrm{PL}}$, which is a function of the boundary layer's heat transfer coefficient, $\alpha_{f}$, and the base material's thickness, $\delta$. This implies that a weld cooling time, $\Delta t T_{1} / T_{2}$, in a forced flow of fluid can now be calculated by an ordinary engineering calculator and thus enabling suitable welding parameters to be determined. The magnitude of $k_{\mathrm{PL}}\left(\alpha_{f}, \delta\right)$ has been established by regression analysis of results from a parametric Finite Element Analysis, FEA, series of a total number of 112 numerical simulations.

Furthermore, the result of the regression analysis has been validated and verified by a welding experiment series accomplished on an in-house designed and constructed in-service welding rig. The principle design of the welding rig as well as its instrumentation, a PC based Data Acquisition system, is described. In addition a method to measure the weld metals cooling time, $\Delta t T_{1} / T_{2}$, by means of thermocouple elements is described.

Finally, the algorithm presented in this research study been proved feasible for commercial in-service welding operations of fine-grained carbon and carbon-manganese steels with a maximum Carbon Equivalent (IIW), Ce, of 0.32 .
\end{abstract}

Keywords: TIG, FEA, FEM, DAQ, Dt 8/5, welding, heat transfer, boundary layer, data acquisition, in-service welding, forced flow of fluid, cooling time 


\section{Preface}

This thesis has been carried out at the Department of Shipping and Marine Technology, Chalmers University of Technology, Göteborg, Sweden. The thesis is based on the work contained in the papers listed below:

\section{Paper A}

Lindstrorm, P., and Ulfvarson, A., 2002, "Weld Repair of Shell Plates During Seagoing Operations", 21st International Conference on Offshore Mechanics and Arctic Engineering, ASME

\section{Paper B}

Lindström, P., and Ulfvarson, A., 2003, "An Experimental Rig for Verification of the Mechanical Properties of Welds produced at In-service Welding", $22^{\text {nd }}$ International Conference on Offshore Mechanics and Arctic Engineering, ASME

\section{Paper C}

Lindström, P., 2005, "Heat transfer Prediction of In-Service Welding In a Forced Flow of Fluid", Submitted for publication in the Journal of Offshore Mechanics and Arctic Engineering, ASME, 2005 


\section{Contribution to Co-authored Papers}

Two of the papers were prepared in collaboration with a co-author. The author of this thesis took major responsibility for the work in both of the papers.

\section{Paper A}

Responsible for the planning of the paper.

Implemented and carried out the numerical simulations.

Carried out the weld experiment.

Wrote the paper

\section{Paper B}

Responsible for the planning of the paper.

Carried out the weld experiment.

Wrote the paper 



\section{List of Content}

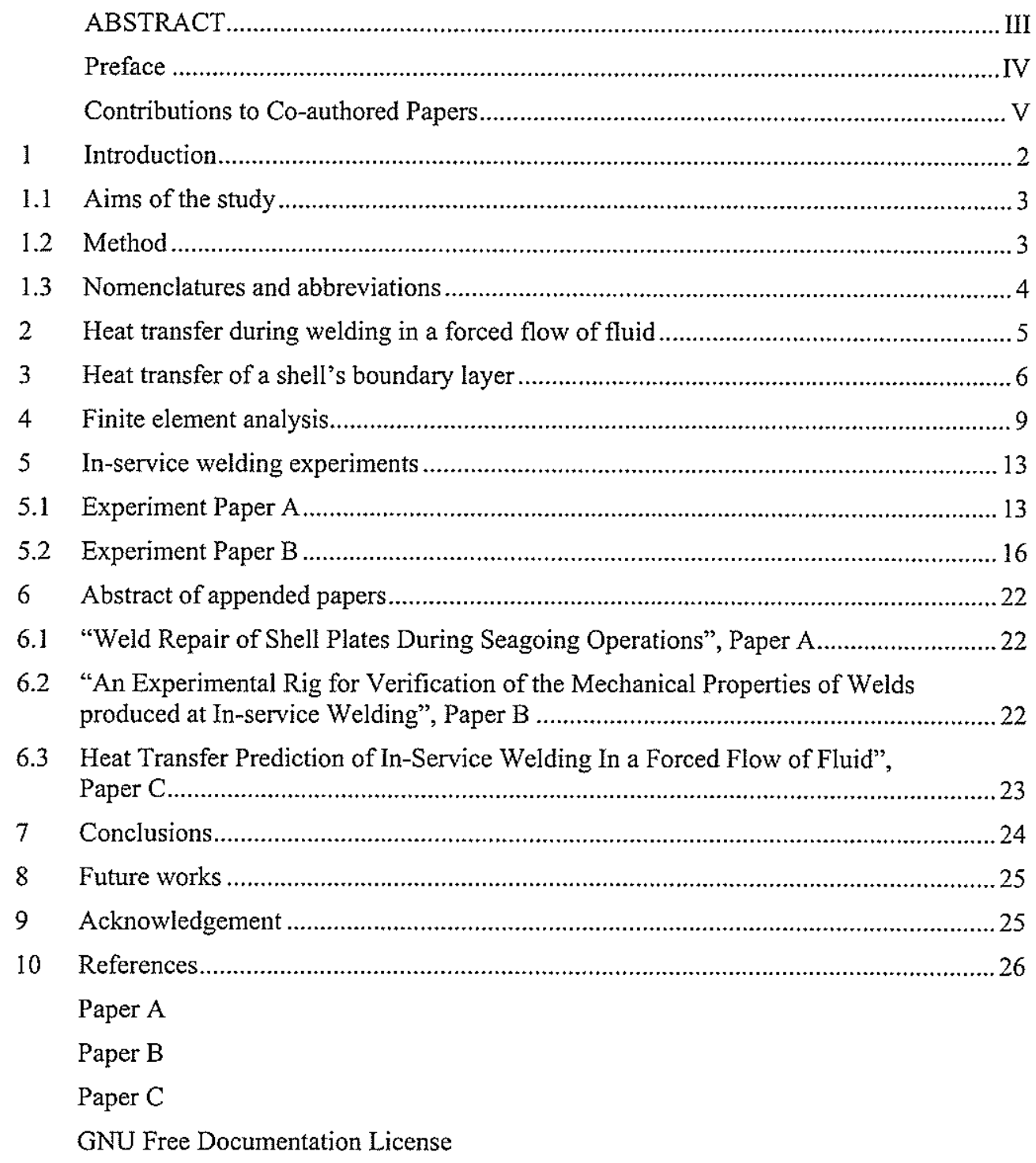




\section{Review and Summary of Thesis}

\section{Introduction}

Five years ago, in 1999, the shell plating below the waterline of two (2) ice-classed ships was repaired by welding during a sea-going operation without pre-heating. On average, about $2000 \mathrm{~kg}$ of consumables were deposited on the shell plating of each ship. The plating was affected by an enhanced cooling rate due to the forced flow of seawater at a speed of $13-16$ knots. The classification society approved the repairs as permanent. One (1) of the ships is still navigating in waters restricted to ships with ice-class notation during the winter season. No problems have been reported that have been associated with the weld repair. As a result, the repair work being carried out during normal operation showed that the repair cost was reduced by about $85 \%$ compared to traditional dry-docking.

The demand for this technique has arisen from the request from the ship's operator to make it possible for the safe repairs of their precious ships without taking them out of operation [1]. The strength of the shell plating after welding is determined by its metallurgic structure, which is dependent on the cooling rate, its chemical composition and the original grain size of the base material [2]. The physical principles of welding shell plates affected by a forced flow of fluid on their reverse side are the same as for welding on the circumference of a tube containing a forced flow of fluid in so called Hot-tapping. Fig 1.
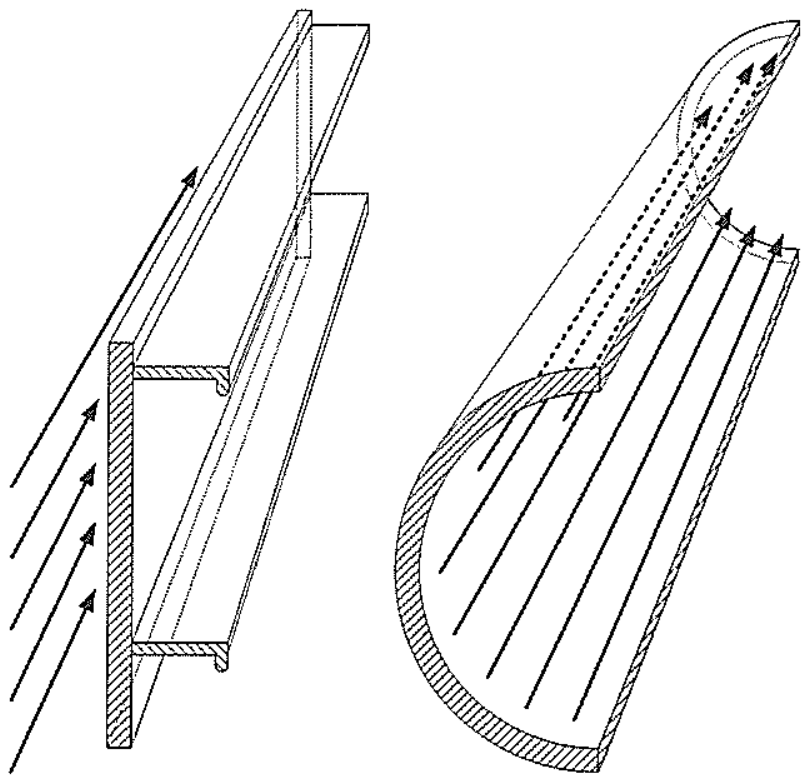

Fig 1. A Shell plate (left) and pipe (right) affected by a forced flow of fluid.

A greater number of Hot-tapping operations have been published compared to the number of shell plate repairs below the waterline during voyage. Consequently, the-state-ofthe-art survey has been carried out against Hot-tapping and consisted of interviews and literature studies. 
Only one of the organizations interviewed, all recognized to be engaged in Hot-tapping operations and research, have been prepared to discuss the way in which they calculate the welding parameters while developing Hot-tapping Welding Procedure Specifications, WPS [3]. For the time being, some Best Practice for Hot-tapping is available through consultants such as TWI, The Welding Institute, and EWI, Edinson Welding Institute. Due to high costs, the afore-mentioned documents have not been reviewed.

The Edinson Welding Institute, EWI, USA, have developed a rig for the qualifying of welders and Welding Procedure Specifications, WPS, to be used during the in-service welding of pipelines. Due to the lack of information on dimensions and particulars of the water flow it is not possible to establish that a complete developed boundary layer is created by the EWI rig [4]. Further-more, researchers from the University of Alberta, Department of Chemical and Materials Engineering, Canada, have reduced the cooling rate of the EWI rig by means of pressurisation of various fluids with zero velocity [5].

Based on established procedures amongst welding engineers, it is presumed that the stateof-the-art in Hot-tapping will include the use of the following precautions, singly and/or in combination [6]:

- Low carbon equivalent of the base material in order to prevent martensite formation.

- Pre-heating the base material in order to prolong the cooling time between $500^{\circ}-800^{\circ} \mathrm{C}$.

- The use of a low hydrogen consumable in order to prevent hydrogen embrittlement.

- The use of austenitic consumables in order to prevent hydrogen embrittlement.

- Multi-string welding with an approximate $50 \%$ overlap giving about $80 \%$ post-heat treatment.

- A speed of the fluid flow above $1 \mathrm{~m} / \mathrm{s}$, to avoid the formation of gas pockets.

For the sake of environmental issues, safety and technical convenience the optimal fluid during welding experiments with high-heat transfer is found to be fresh water in the state of liquid. If a low-heat transfer coefficient is to be simulated, air with $100 \%$ humidity is found to be a suitable experimental fluid, if appropriate safety precautions are taken [7].

\subsection{Aims of the study}

The main objective of this research study is to derive and establish an algorithm on the basis of Rosenthal's heat flow solutions and boundary layer approximations predicting the heat transfer during in-service welding in a forced flow of fluid. The algorithm is intended to be used by organisations and individuals that have an interest in the heat transfer prediction of in-service welding in a forced flow of fluid.

\subsection{Method}

The general method applied is System Engineering, SE, based on David G. Ullman's principles [8]. As the art of arc-welding is multi disciplinary a range of methods has been utilised. The methods used are: Literature reviews, interviews, boundary layer approximations, FEM, welding experiments, Data Acquisitioning and metallography as well as tweaking of PC-systems. 


\subsection{Nomenclatures and abbreviations used}

$\begin{array}{ll}\text { A } & \text { area, } \mathrm{m}^{2} \\ \mathrm{C} & \text { heat capacity, } \mathrm{J} /{ }^{\circ} \mathrm{C} \\ \mathrm{Cp} & \text { heat capacity at constant pressure, } \mathrm{J} /{ }^{\circ} \mathrm{C} \\ \mathrm{I} & \text { current, } \mathrm{A} \\ \mathrm{L} & \text { length, } \mathrm{m} \\ \mathrm{Nu} & \text { Nusselt's number, dimensionless parameter } \\ \mathrm{Pr} & \text { Prandtl number, dimensionless parameter } \\ \mathrm{Q} & \text { heat, } \mathrm{J} \\ \mathrm{Q} & \text { weld heat input, } \mathrm{J} / \mathrm{m} \\ \mathrm{Re} & \text { Reynold's number, dimensionless parameter } \\ \mathrm{T} & \text { temperature in Celsius, }{ }^{\circ} \mathrm{C} \\ \mathrm{TIG} & \text { Tungsten Inert } \mathrm{Gas} \text { welding } \\ \mathrm{U} & \text { main, } \mathrm{V} \\ \mathrm{V} & \text { velocity, } \mathrm{m} / \mathrm{s} \\ \mathrm{WPS} & \text { Welding Procedure Specification } \\ \mathrm{c} & \text { specific heat, } \mathrm{J} /\left(\mathrm{kg}{ }^{\circ} \mathrm{C}\right) \\ \mathrm{k} & \text { thermal conductivity, } \mathrm{W} /\left(\mathrm{m}{ }^{\circ} \mathrm{C}\right) \\ \mathrm{k}_{\mathrm{PL}} & \text { apparent thermal conductivity, } \mathrm{W} /\left(\mathrm{m}{ }^{\circ} \mathrm{C}\right) \\ \mathrm{q} & \text { volumetric flow of fluid, } \mathrm{m}^{3} / \mathrm{s} \\ \mathrm{t} & \text { time, } \mathrm{s} \\ \left(\Delta t \mathrm{~T}_{1} / \mathrm{T}_{2}\right) & \text { weld cooling time, } \mathrm{s} \\ \alpha & \text { coefficient of heat transfer, } \mathrm{W} /\left(\mathrm{m}^{2}{ }^{\circ} \mathrm{C}\right) \\ \delta & \text { thickness, } \mathrm{m} \\ \eta & \text { weld efficiency factor } \\ \rho & \text { density, } \mathrm{kg} / \mathrm{m}^{3} \\ \mathrm{f} & \text { kinematic viscosity, } \mathrm{m}^{2} / \mathrm{s} \\ \pi & \text { dimensionless parameter } \\ \mathrm{f} & \text { fluid } \\ \text { distance in } \mathrm{x} \text { direction, } \mathrm{m} \\ \end{array}$




\section{$2 \quad$ Heat Transfer During Welding In a Forced Flow of Fluid}

When welding in ferritic materials, the most important parameter is the cooling time from $800^{\circ} \mathrm{C}-500^{\circ} \mathrm{C}, \Delta \mathrm{t} 8 / 5$, as it will govern the metallurgical structure of the Heat Affected Zone, $\mathrm{HAZ}$. Independently of each other's work analytic solutions to the problem of arc-weld cooling time, have been found by $\mathrm{D}$. Rosenthal and N. Rykalin. Amongst welding engineers these equations are known as the "Rosenthal's 3D-Heat and 2D-Heat flow solutions", equations (1) and (2), which should be used for thick and thin materials, respectively. The weld heat input, $\mathrm{Q} w$, is calculated with equation (3) [9] [10].

$$
\begin{aligned}
& \Delta t T_{2} / T_{1}=\frac{Q_{w}}{2 \pi k}\left(\frac{1}{T_{1}-T_{0}}-\frac{1}{T_{2}-T_{0}}\right) \\
& \Delta t T_{2} / T_{1}=\frac{Q_{w}}{2 \pi k \rho c}\left(\frac{1}{\left(T_{1}-T_{0}\right)^{2}}-\frac{1}{\left(T_{2}-T_{0}\right)^{2}}\right) \\
& Q_{w}=\frac{U \cdot I}{V_{w}} \cdot \eta
\end{aligned}
$$

A selection of appropriate equation, for the actual case, may be done with the support of equation (4). There, $\delta_{3 \mathrm{D}}$ is the $3 \mathrm{D}-2 \mathrm{D}$ heat-flow limit thickness [11].

$$
\delta_{3 D} \geq\left[Q_{w} \cdot 10^{-6}\left[\frac{4,3 \cdot 10^{-2}-4,3 \cdot 10^{-5} \cdot T_{0}}{0,67-5 \cdot 10^{-4} \cdot T_{0}}\right] \cdot\left[\frac{1}{500-T_{0}}+\frac{1}{800-T_{0}}\right]\right]^{0.5}
$$

Rosenthal's solutions imply, amongst other simplifications, that the heat flow through the surface of the base materials has to be neglected [12]. This is a major disadvantage, as it limits the solution's application to weld joint problems with very low boundary layers values, such as still air and vacuum [13]. The energy in the melt pool of a weld will mainly disappear in the form of a heat flux in the solid and the heat flow will occur in three (3) directions $x, y$ and $\mathrm{z}$.

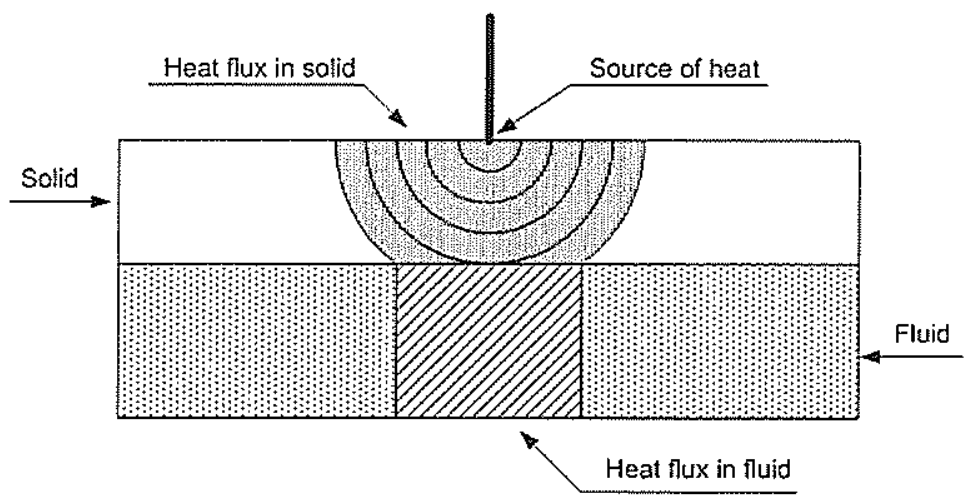

Fig. 2 A cross-section view of the heat flux from a melt pool into flow of fluid. The arrow from right is marking the fluid. 
When welding a steel plate of moderate thickness, a part of the heat flux will pass through the structure and affect the temperature on the reverse side. The boundary-forming substance, solid or fluid, will be affected and continue the heat transfer. If the boundaryforming substance is a fluid, the heat flux transfer will be a combination of radiation and convection. In an infinitely thin boundary plane, the heat transfer will transform from spherical to cylindrical. The cylinder's centre axis is normal to the surface, Fig 2, [14].

Nevertheless, through the introduction of the apparent thermal conductivity, $\mathrm{k}_{\mathrm{PL}}$, equation (5), it has been found feasible to derive the weld cooling time of weld joints affected by a boundary layer, $\Delta t T_{1} / T_{2}$, from Rosenthal's $3 \mathrm{D}-$ Heat flow equation, equations (6) and (7).

$$
\begin{aligned}
& k_{P L}=k_{P L}\left(\alpha_{f}, \delta\right) \\
& \Delta t T_{2} / T_{1}=\frac{Q_{w}}{2 \pi k_{P L}}\left(\frac{1}{T_{1}-T_{0}}-\frac{1}{T_{2}-T_{0}}\right) \\
& k_{P L}=\frac{Q_{w 1}}{\left(2 \cdot \pi \cdot \Delta t T_{1} / T_{2}\right)} \cdot\left(\frac{1}{\left(T_{2}-T_{0}\right)}-\frac{1}{\left(T_{1}-T_{0}\right)}\right)
\end{aligned}
$$

\section{Heat Transfer of a Shell's Boundary Layer}

The boundary layer of a shell plate will be laminar at the bow of the ship and as a function of the length and the velocity successive transform to a turbulent boundary layer. The turbulent layer will continue to grow as a function of the length of the shell plate giving a longer shell plate a greater boundary layer, Fig 3, [15] [16].

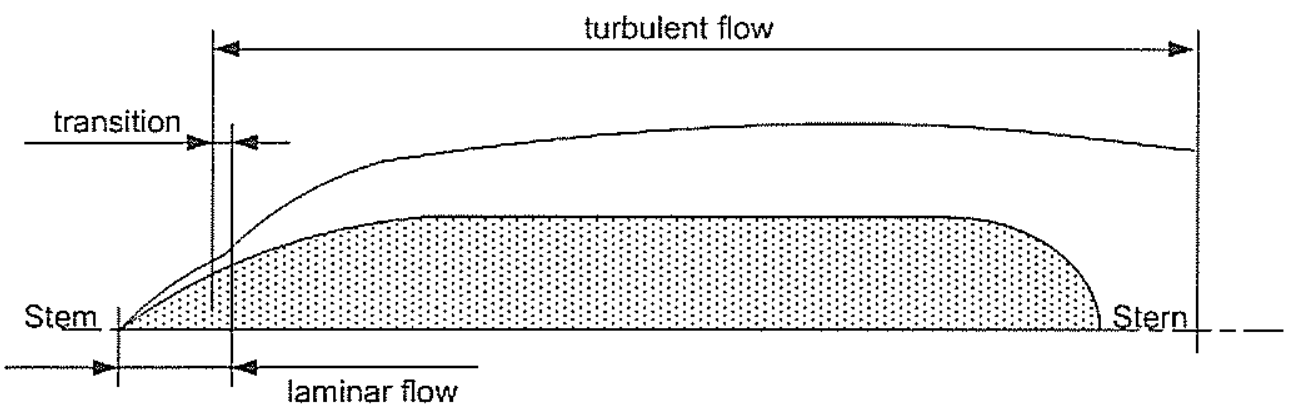

Fig 3. An illustration of the sea's boundary layer of a ship's shell plate, ship's stem left and the stern on the right side

The following algorithm gives the analytic solution on the heat transfer of the shell plate's boundary layer. The limitation of its application is that it is only applicable in a single phase flow, i.e. the fluid has to be in liquid or gas form. In case of a two-phase flow the equation is inadequate. This implies that it is only applicable when the coefficient of heat transfer, $\alpha_{f}$, exceeds about $1 \mathrm{~kW} /\left(\mathrm{m}^{2}{ }^{\circ} \mathrm{C}\right)$ 
The heat transfer coefficient of a fully developed turbulent boundary layer of a fluid, $\alpha_{f}$, along a flat plate or internally in a pipe is basically calculated by the same algorithm. Along a flat plate, the coefficient of heat transfer, $\alpha_{f}$, is calculated with equations (8), (9), (10) and (11).

$$
\begin{aligned}
& \operatorname{Pr}=\frac{v_{f} \cdot \rho_{f} \cdot C p_{f}}{k_{f}} \\
& \operatorname{Re}_{x}=\frac{V_{f} \cdot L_{x}}{v_{f}} \\
& N u_{x}=\frac{0.030 \cdot \operatorname{Re}_{x}^{\frac{4}{5}} \cdot \operatorname{Pr}}{1+1.3 \cdot \operatorname{Pr}^{-\frac{1}{6}} \cdot \operatorname{Re}_{x}^{-\frac{1}{10}} \cdot(\operatorname{Pr}-1)} \\
& \alpha_{f}\left(V_{f}, L_{f}\right)=\frac{\left(k_{f} \cdot N u_{x}\right)}{L_{f}}
\end{aligned}
$$

The Prandtl number, Pr, describes the thermal properties of a boundary layer and it is a dimensionless coefficient. The dimensionless coefficient Nusselt's number, Nu, describes the sub-viscous layer of the boundary layer and it is within the sub-viscous layer that the heat transfer from the shell plate to the boundary layer will occur. The thinner the sub-viscous layer the higher the rate of the heat transfer will be. Inside a pipe the heat transfer coefficient, $\alpha_{f}$, is calculated with equations (8), (12), (13) and (14).

$$
\begin{aligned}
& \operatorname{Pr}=\frac{v_{f} \cdot \rho_{f} \cdot C p_{f}}{k_{f}} \\
& \operatorname{Re}_{d}=\frac{V_{f} \cdot d}{v_{f}} \\
& N u_{d}=\frac{0.038 \cdot \operatorname{Re}_{d}^{\frac{3}{4}} \cdot \operatorname{Pr}}{1+1.5 \cdot \operatorname{Pr}^{-\frac{1}{6}} \cdot \operatorname{Re}_{d}^{-\frac{1}{8}} \cdot(\operatorname{Pr}-1)} \\
& \alpha_{f}\left(V_{f}, d\right)=\frac{\left(k_{f} \cdot N u_{d}\right)}{d}
\end{aligned}
$$

This relation gives a possibility to create the heat transfer on the reverse side of a shell plate for a specific welding situation by means of a controlled flow of fluid through a tube with recognized properties, Diagrams 1 and 2, [17] [18].

To make the afore-mentioned algorithm useable, the magnitude of the apparent thermal conductivity, $k_{P L}$, equation (7), should be determined. Values to be used, time $(t)$ and temperatures $\left(T_{n}\right)$, will be given from numerical welding simulations verified by welding experiments. 


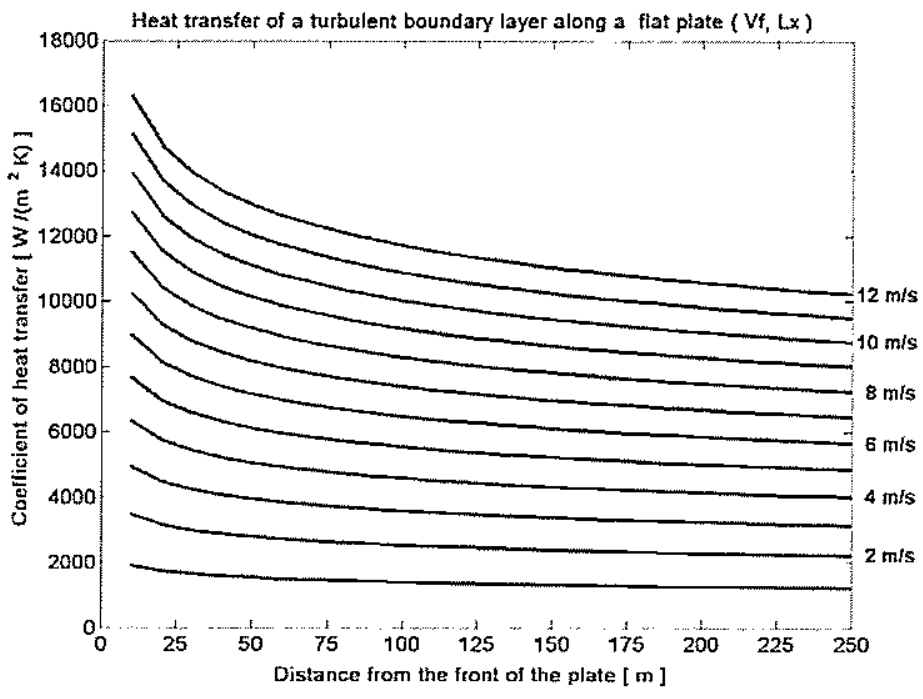

Diagram 1. The diagram shows the heat transfer coefficient of a fully developed turbulent boundary layer of fresh water along a flat plate at the velocities 1 to $12 \mathrm{~m} / \mathrm{s}$.

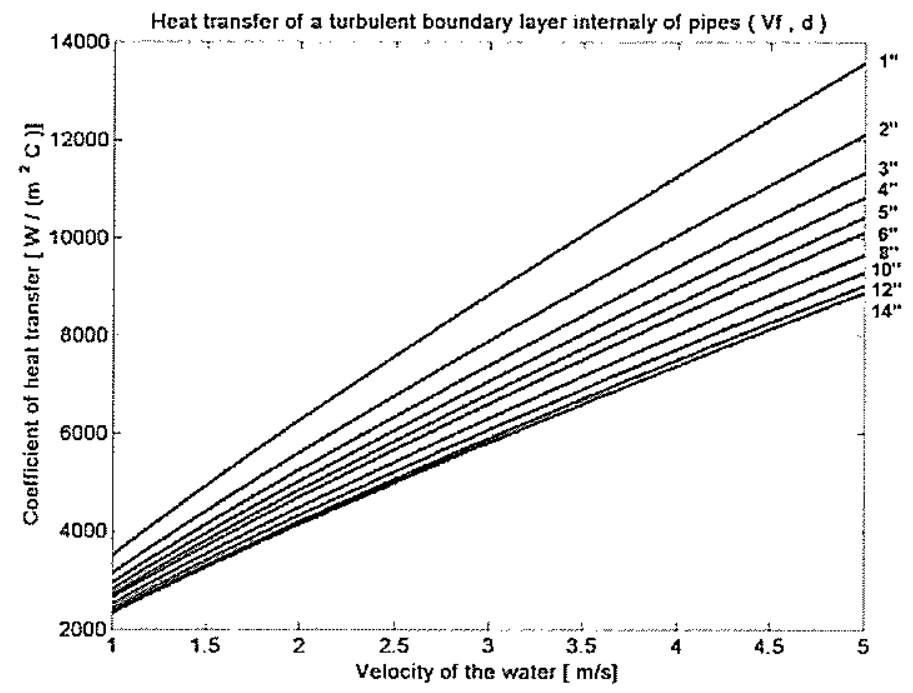

Diagram 2. The diagram shows the heat transfer coefficient of a completely developed turbulent boundary layer of fresh water internally of ASTM Schedule 80 pipes, $\varnothing 1 "-14 "$.

Physical properties of the water: $\mathrm{T}=5^{\circ} \mathrm{C}, \mathrm{Cp}_{f}=4206 \mathrm{~J} /\left(\mathrm{kg}^{\circ} \mathrm{C}\right), \rho_{f}=1000 \mathrm{~kg} / \mathrm{m}^{3}, \mathrm{k}_{f}=0.568 \mathrm{~W} /\left(\mathrm{m}^{\circ} \mathrm{C}\right), v_{f}$ $=1.519 \cdot 10^{-6} \mathrm{~m}^{2} / \mathrm{s}, \operatorname{Pr}=11.25$ 


\section{$4 \quad$ Finite Element Analysis}

A total number of 112 Finite Element Analyses, FEA, have been solved in order to establish the function of the apparent thermal conductivity, $\mathrm{k}_{\mathrm{PL}}$, equation (7). FEMLAB (Versions 2.2 and 2.3), a commercial Finite Element Method (FEM) software, was utilised to simulate the cooling time, $\Delta t T_{2} / T_{1}$, at Tungsten Inert Gas, TIG, welding of steel plates affected by a forced flow of fluid on its reversed side. All simulations were executed on an inhouse built Linux workstation with the following general configuration: motherboard MSI Pro266TD Master-LR2, CPU $2 \times$ Intel Tualatin $1,13 \mathrm{GHz}$ with $512 \mathrm{~K}$ L2 cache, RAM $2 \mathrm{x}$ 1,024 GB, OS SuSE Linux 8.0 Professional with its standard SMP-kernel [19].

The principal design of the models used is a rectangular steel plate $(0.50 \times 0.08 \mathrm{~m})$ with the thicknesses, $\delta 5,7.5,10,15 \ldots$ to $75 \mathrm{~mm}$, exposed to seven (7) different heat transfer coefficients, $\alpha_{f}$, they are: $1 \mathrm{~W} /\left(\mathrm{m}^{2} \mathrm{C}\right) ; 1 \mathrm{~kW} /\left(\mathrm{m}^{2} \mathrm{C}\right) ; 2 \mathrm{~kW} /\left(\mathrm{m}^{2} \mathrm{C}\right) ; 4 \mathrm{~kW} /\left(\mathrm{m}^{2} \mathrm{C}\right) ; 6 \mathrm{~kW} /\left(\mathrm{m}^{2}\right.$ $\mathrm{C}) ; 8 \mathrm{~kW} /\left(\mathrm{m}^{2} \mathrm{C}\right)$ and $10 \mathrm{~kW} /\left(\mathrm{m}^{2} \mathrm{C}\right)$. The models are meshed by parabolic tetrahedron elements ( 4 corner nodes and 6 side nodes). The FEM-models are time-dependent and simulate the heat input of TIG, Tungsten Inert Gas, welding in the form of a rectangle $(2 \times 1$ $\mathrm{mm}$ ) travelling longitudinally on the edge of the plate's top surface with a time-step frequency of $1 \mathrm{~Hz}$. WPS used: $\mathrm{Q}_{W} 1,5 \cdot 10^{6} \mathrm{~J} / \mathrm{m}$; I $375 \mathrm{~A} ; \mathrm{U} 20 \mathrm{~V} ; \eta 1,0 ; \mathrm{V}_{\mathrm{W}} 5 \cdot 10^{-3} \mathrm{~m} / \mathrm{s}$; Heat-input $\left(\mathrm{W} / \mathrm{m}^{2}\right) \mathrm{Q}_{\mathrm{W}}\left(\mathrm{x}>\mathrm{t}-5 \cdot 10^{-4}-2 \cdot 10^{-3}\right)\left(\mathrm{x}<\mathrm{V}_{\mathrm{W}} \mathrm{t}-5 \cdot 10^{-4}\right)$; The base material's physical properties were: $\mathrm{T}_{0} 10^{\circ} \mathrm{C} ; \rho 7850 \mathrm{~kg} / \mathrm{m}^{3} ; \mathrm{C} 460 \mathrm{~J} /{ }^{\circ} \mathrm{C} ; \mathrm{k} 45 \mathrm{~W} /\left(\mathrm{m}{ }^{\circ} \mathrm{C}\right)$. Fig 4.



Fig 4. The geometry of FEM-models used to solve the cooling time, $\Delta t T_{2} / T_{I}$, in $20 \mathrm{~mm}$ thick steel plates. 
On completion of the weld simulations the results, $\Delta t T_{2} / T_{1}$, were used to calculate the apparent thermal conductivity, $\mathrm{k}_{\mathrm{PL}}$, by equation (7). This was followed by a regression analysis in order to establish the function of the thermal conductivity, $\mathrm{k}_{\mathrm{PL}}$. The regression

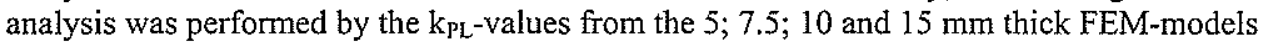
affected by the heat transfer coefficients, $\alpha_{f}, 1-10 \mathrm{~kW} /\left(\mathrm{m}^{2} \mathrm{C}\right)$. The reasons for this are that the $3 \mathrm{D}-2 \mathrm{D}$ heat flow limit thickness, $\delta_{3 \mathrm{D}}$, is indicated as being about $17 \mathrm{~mm}$, equation (4) and it is known that the water's heat transfer coefficient, $\alpha_{f}$, is unstable, due to boiling phenomena, at values less than $1 \mathrm{~kW} /\left(\mathrm{m}^{2} \mathrm{C}\right)$.

These values are used to compile a $\mathrm{k}_{\mathrm{PL}}$-diagram to facilitate the work with the regression analysis. Its resolution is dependent on the time-step frequency $(1 \mathrm{step} / \mathrm{s})$ of the FEM-models used. Even so, the result falls within a narrow band of equations, Diagram 3.

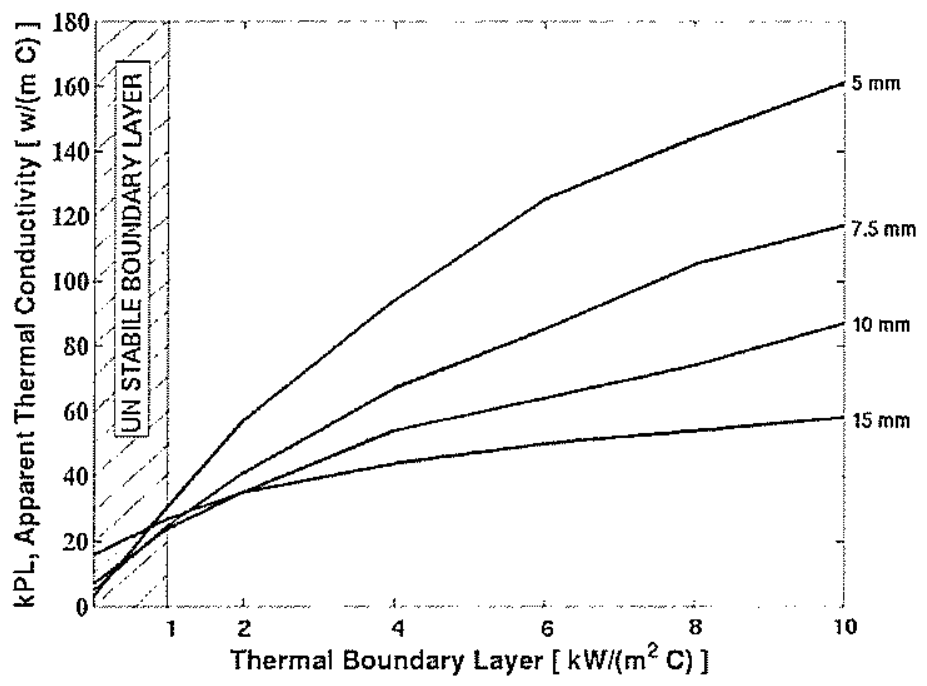

Diagram 3. The diagram indicates the $\mathrm{k}_{\mathrm{PL}}$-function's form; its resolution depends on the timestep frequency used, 1 step/s.

The regression analysis was performed by the least-squares method. As a result thereof, the function of the apparent thermal conductivity, $\mathrm{k}_{\mathrm{PL}}$, was approximated and a diagram for the thicknesses 5,7.5, 10 and $15 \mathrm{~mm}$ could be compiled, equation (12), Diagram 4.

$$
k_{P L}\left(\alpha_{f}, \delta\right)=1,45 \cdot \alpha^{0,65} \cdot \delta^{-0.78}
$$

A welding experiment series, of a total number of six (6) longitudinal TIG-weld seams in a forced flow of fluid, was carried out to validate the regression curves obtained. The experimental welding was performed on an "In-service welding test rig" designed and built for this specific subject. It consists basically of a $7.4 \mathrm{~m}$ long $\emptyset 48.3 \times 4.5 \mathrm{~mm}$ tube, exposed to an internal forced flow of water. 6.0 metres of the tube's length constituted the entrance, about 152 diameters, and the remaining $1.4 \mathrm{~m}$ constituted the test coupon. An outlet nozzle with a drain hose was welded to maintain a slight pressure in the rig and move the outlet water from the welding area to a spigot. To register the water flow during the experiments, a volume meter, resolution $1 \cdot 10^{-3} \mathrm{~m}^{3}$, was connected to the inlet side of the rig. 


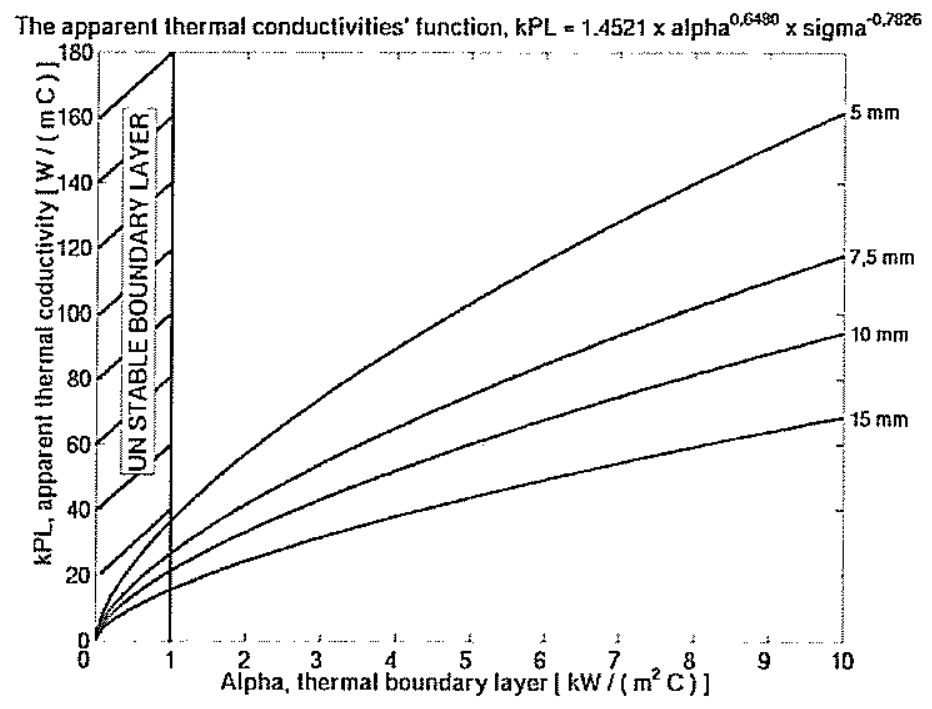

Diagram 4. The diagram indicates the graphs of the $k_{\mathrm{PL}}$-function

The welding experiments were accomplished by mechanised TIG, Tungsten Inert Gas, and the equipment used was an EWM TRITON 260 TIG welding machine longitudinally manipulated by an ESAB Railtrack FW 1000. During the welding of the six (6) seams, the main, $U(V)$, current, I (A), and the weld cooling time, $\Delta t T_{2} / T_{1}(s)$, were sampled at a frequency of $1 \mathrm{kHz}$ by an in-house designed weld Data Acquisition system, DAQ, named MUGIN. [20]

During processing and analysis of the experiment data it was found that three (3) of the six (6) acquisitions had resulted in useable weld cooling times, $\Delta t T_{2} / T$. Two (2) of these had been recorded during welding with a water flow of $0.5 \cdot 10^{-3} \mathrm{~m}^{3} / \mathrm{s}$. This offered a heat transfer coefficient, $\alpha_{f}$, of $10.4 \mathrm{~kW} /\left(\mathrm{m}^{2}{ }^{\circ} \mathrm{C}\right)$ and the remaining one (1) had been recorded during welding at a water flow of $1 \cdot 10^{-3} \mathrm{~m}^{3} / \mathrm{s}$, giving a heat transfer coefficient, $\alpha_{f}$, of $18.5 \mathrm{~kW} /\left(\mathrm{m}^{2}\right.$ ${ }^{\circ} \mathrm{C}$ ). The successfully recorded parameters of the welds are stated with the calculated values of $k_{\mathrm{PL}}$ (by using equation 12) in Table 1.

\begin{tabular}{|c|c|c|c|}
\hline TABLE I & & & \\
\hline Parameters & Weld 1 & Weld 2 & Weld 3 \\
\hline$\alpha$ & $10.4\left(\mathrm{~kW} / \mathrm{m}^{2}{ }^{\circ} \mathrm{C}\right)$ & $10.4\left(\mathrm{~kW} / \mathrm{m}^{2}{ }^{\circ} \mathrm{C}\right)$ & $18.5\left(\mathrm{~kW} / \mathrm{m}^{2}{ }^{\circ} \mathrm{C}\right)$ \\
\hline$\eta$ & 0.65 & 0.65 & 0.65 \\
\hline $\mathrm{Q}_{\mathrm{w}}$ & $0.52(\mathrm{~kJ} / \mathrm{mm})$ & $0.52(\mathrm{~kJ} / \mathrm{mm})$ & $0.52(\mathrm{~kJ} / \mathrm{mm})$ \\
\hline$\Delta \mathrm{T} 8 / 5$ & $1.44(\mathrm{~s})$ & $1.31(\mathrm{~s})$ & $0.99(\mathrm{~s})$ \\
\hline $\mathrm{k}_{\mathrm{PL}}$ given by experiment & $158\left(\mathrm{~W} / \mathrm{m}^{2 \circ} \mathrm{C}\right)$ & $173\left(\mathrm{~W} / \mathrm{m}^{2 \circ} \mathrm{C}\right)$ & $228\left(\mathrm{~W} / \mathrm{m}^{2 \circ} \mathrm{C}\right)$ \\
\hline $\mathrm{k}_{\text {pL. }}$ predicted by Eq. (12) & $179\left(\mathrm{~W} / \mathrm{m}^{2 \circ} \mathrm{C}\right)$ & $179\left(\mathrm{~W} / \mathrm{m}^{2 \circ} \mathrm{C}\right)$ & $261\left(\mathrm{~W} / \mathrm{m}^{20} \mathrm{C}\right)$ \\
\hline
\end{tabular}


It should be noted that the weld heat-efficiency factor used, $\eta=0,6$, is in strict accordance with the standards EN 1011-1 and prEN ISO 15614 [21] [22] [23]. This raises the questions if the $\eta$-value to be used should be 0.55 or 0.65 . Numerous scientific papers in the subject have been published only during the last 10 years and there is still no equation to calculate the value of the arc efficiency factor $\eta$ [24]. Even so, it is strongly believed that the arc efficiency factor $\eta$ has more likely been 0.65 than 0.55 due to following facts:

- Welding was carried out on carbon-manganese steel, which emits a relatively small amount of light scatter (energy radiation) compared to welding in stain less steel.

- Welding was carried out by mechanical means giving a controlled short arc-length.

- The torch angle was $90^{\circ}$, in all directions, to the plan of welding.

It is also believed that the precision of the $\mathrm{k}_{\mathrm{PL}}$-function validation will increase with an experimental series in a larger scale. The accuracy of the temperature reading may be improved by the usage of an other type of thermocouple, i.e. type S. [25]

Even so, the precision of the algorithm described in this study is considered as being suitable enough for industrial in-service welding operations in the forced flow of fluid of finegrained carbon and carbon-manganese steels with a maximum Carbon Equivalent (IIW), $\mathrm{Ce}$, of 0.32 [13] [26]. 


\section{$5 \quad$ In-Service Welding Experiments}

\subsection{Experiment Paper A.}

A welding experiment was carried out at ESAB Process Centre, Gothenburg, Sweden, on 9,15 and 16 June 2000 , during which a model simulating a shell plate of a ship in port was used. During simulation of welding below the water line a quantity of about 6 litres $/ \mathrm{min}$ was circulating to simulate a perturbed water flow that can be observed on the water surface around ships in port. As the weld test model was symmetr-ical, dry welding was conducted on one of the flat sides of the test model and wet welding on the opposite side. Three test coupons could be taken from the dry side and three from the wet side of the model. The weld joints produced were full-penetration fillet welds, representing the heat input at renewal of a shell plate stiffener. Attached to the back of the welds was a Thermocouple type K covered by protecting putty. During the welding sequence, the thermocouples were connected to a temperature logger, Fig 5.
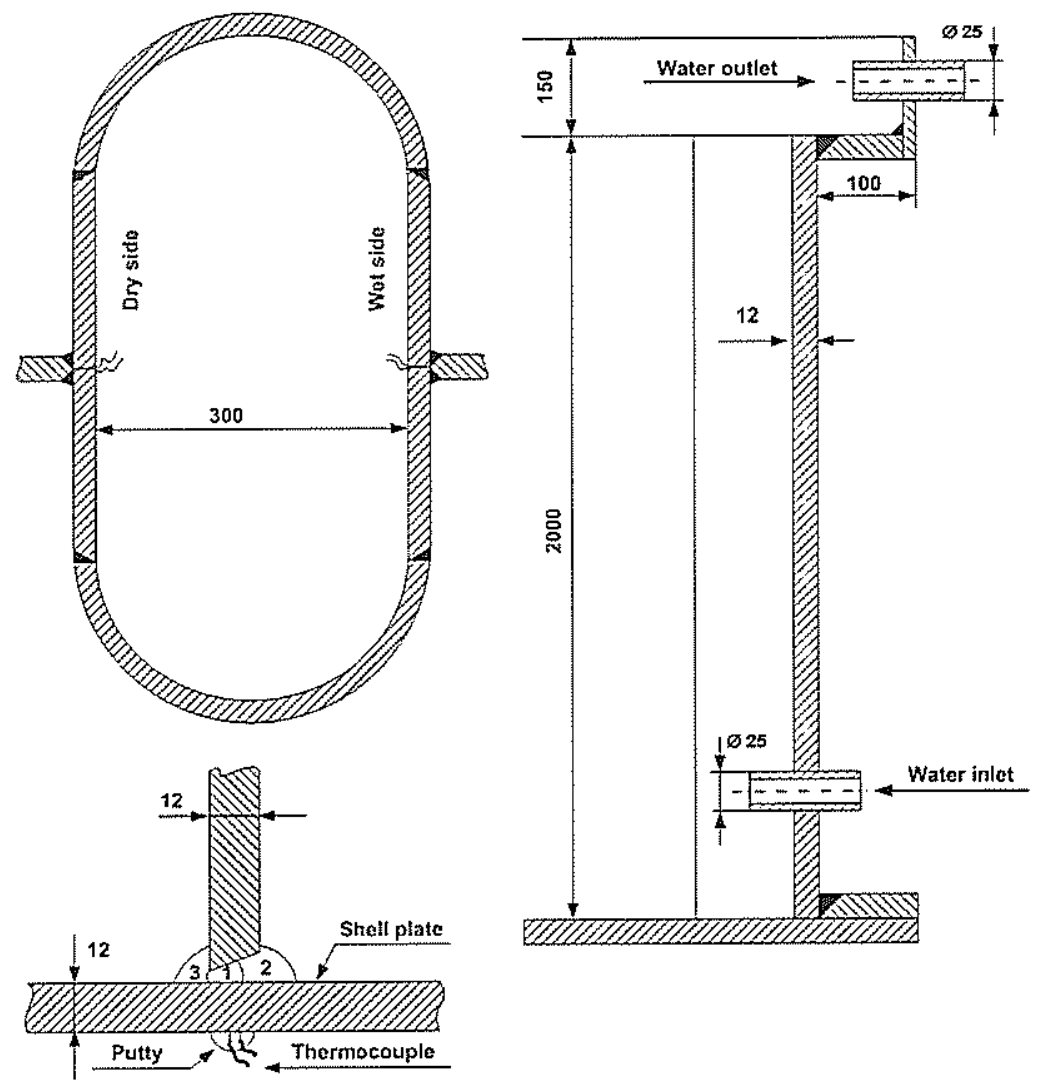

Fig 5. An illustration of the model used, upper left - cross-section view from the top, lower left - weld joint details, Right - details of water in- and out-let 
The material used for the flat sides and the stiffener of the model was: ship steel Grade NV E 36 - normalized condition; Manufacturer SSAB Oxelösund AB; Heat No. 87553160 1; Ce Carbon Equivalent (IIW) 0.40; Chemical Composition in \%: C 0.15; Si 0.42; Mn 1.43; P 0.006 ; S 0.009; Cr 0.02; Ni 0.03; Mo 0.010; V 0.009; Cu 0.01; Al 0.036; Nb $0.031 ; \mathrm{N} 0.010$ and Ti 0.013 . Base material temperature for dry coupons was $20^{\circ} \mathrm{C}$ and wet coupons $17^{\circ} \mathrm{C}$. The WPS used was: FCAW; vertical-up position; DCRP (DC+) connected to an ESAB OK $15.14, \varnothing 1.2 \mathrm{~mm}$ consumable in combination with $100 \% \mathrm{CO}^{2}$ as shielding gas and the heat input of each weld joint's runs was: Run 1: $2.4 \mathrm{~kJ} / \mathrm{mm}$; Run 2: $1.7 \mathrm{~kJ} / \mathrm{mm}$ and for Run $3: 1.7$ $\mathrm{kJ} / \mathrm{mm}$.

During the wet welding, small bubbles $(\varnothing 1-2 \mathrm{~mm})$ were observed on the water surface of the model. The origin could not be established. Nevertheless, a boiling on the backside of the weld cannot be excluded. An analysis of the temperature records from the welding operations show that the temperature on the back of the wet-test coupons had been about $200^{\circ} \mathrm{C}$ lower compared to the temperature of the dry test coupons. The involved parties raised two main questions when the results of the experiment were discussed. Where do the bubbles come from? If the bubbles originate from a boiling film on the back of the weld, do they have a hydrophilic or hydrophobic character [27]?

The hardness testing of the Macro sections of the dry and wet coupons indicated that the hardness is within the tolerances for an acceptable weld in such materials, which is to not exceed 350 HV. The highest single hardness value is found in the HAZ of Run No.2 on a wettest coupon, 335.2 HV.

The analysis of the microstructure in the area of the fusion line on the dry-weld test coupons indicated that the dominating microstructure in the weld metal was acicular ferrite. The microstructure of the coarse grained zone is ferrite with an aligned or non-aligned second phase. Some small grains of martensite or bainite are present in small amounts. The analysis of the microstructure in the area of the fusion line on the wet-weld test coupons indicated that the dominating microstructure in the weld metal was acicular ferrite. The microstructure of the coarse grained zone is martensite. Some small grains of ferrite with an aligned second phase are present in small amounts.

From each weld test coupon, three (3) dry and three (3) wet, two (2) sets of Charpy-V specimens $(5 \cdot 10 \mathrm{~mm})$ were taken out crosswise to the rolling direction of the plate with the $V$-notch along the normal of the surface. One set of each coupon was taken close to the weld, and the other set of specimens was taken close to the back of the plate. Fig 6.

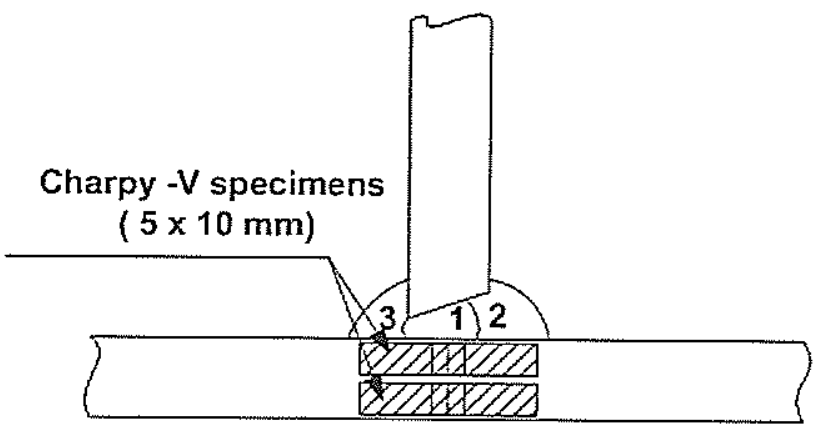

Fig 6. An illustration of the Charpy-V specimen's location in the weld test coupon 
From a test coupon of unaffected base material eleven Charpy-V specimens ( $5 \cdot 10 \mathrm{~mm})$ were taken out close to the surface of the plate, crosswise over the plate's rolling direction with the V-notch along the normal of the surface. The mean impact value of the base material was: 36 J@0 0 ; $34 \mathrm{~J} @-20^{\circ} \mathrm{C} ; 31 \mathrm{~J} @-40^{\circ} \mathrm{C} ; 27 \mathrm{~J} @-50^{\circ} \mathrm{C}$ and $21 \mathrm{~J} @-60^{\circ} \mathrm{C}$.

The Charpy-V specimens from the weld test coupons were tested at a temperature of $-20^{\circ}$ $\mathrm{C}$, giving a toughness of $29.7 \mathrm{~J}$ as the mean value of the dry weld test coupons' reverse side and a toughness of 32.3 Joule as the mean value of the wet-weld test coupons' reverse side. The mean toughness value in the fusion line for dry coupons was $29 \mathrm{~J}$ and $29.3 \mathrm{~J}$ for wet coupons.

The impact-testing result of the unaffected base materials was plotted in a S-curve diagram. With the assumption that the change of the dry and wet weld coupons' mean toughness at $-20^{\circ} \mathrm{C}$ is representative for the S-curve's whole spectrum of new curves for the fusion line, dry-back and wet-back side, were created in the diagram. Diagram 5.

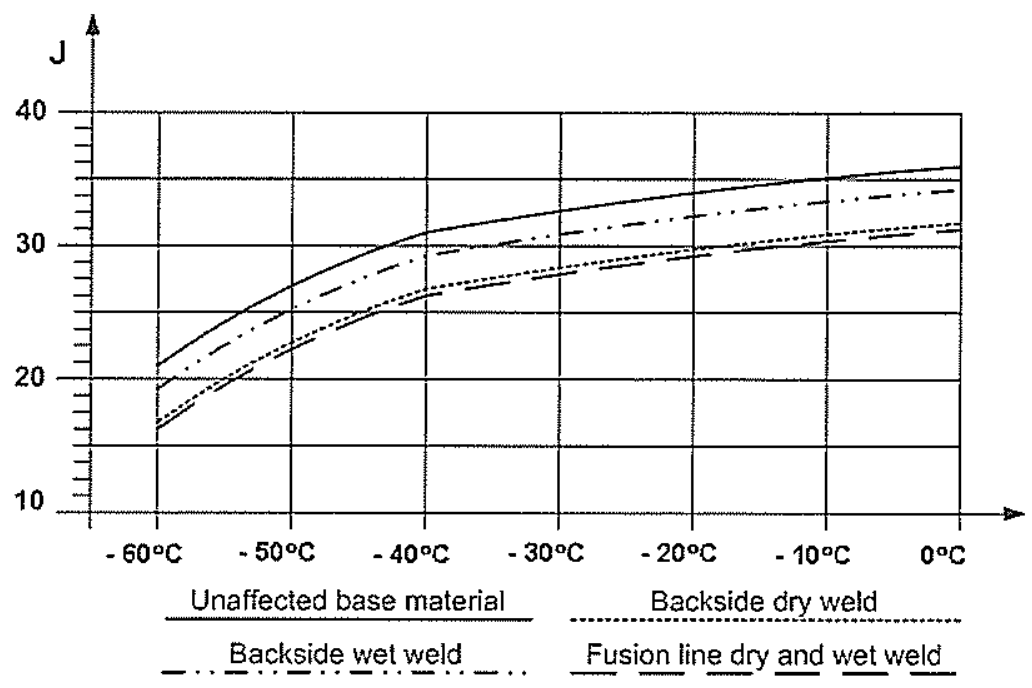

Diagram 5. An S-curve diagram indicating the toughness of the base material, unaffected, reverse side of wet weld, reverse side of dry weld and fusion line.

A comparative analysis of the curves, in Diagram 5, indicates that the toughness has been reduced on all test coupons due to the heat during welding. It is noted that the toughness has been reduced to a greater extent on the dry welding coupons. This may be explained by the fact that the growth has been prevented by the enhanced cooling of the wet coupons in combination with a relatively ductile feature of the martensite in the HAZ. The hardness of the martensite is dependent on the carbon content of the base material, which in this case has a comparatively low value of $0.15 \%$ [28]. The toughness test results of all coupons are in accordance with the requirements of DNV that require the average value of a set of three Charpy-V $(5 \times 10 \mathrm{~mm})$ specimens to be at least $22.7 \mathrm{~J}$ [29]. 


\subsection{Experiment Paper B}

A welding experiment was carried out on an unsheltered pier along the river Göta Älv in the Port of Gothenburg, Sweden, between $10^{\frac{50}{0}}$ and $12^{\frac{40}{}}$ on Saturday 21 December 2002. Weather conditions at the time of the experiment was bright sky, calm air and an air temperature of $-0.3^{\circ} \mathrm{C}$. At the time of the experiment, a total number of twelve (12) welds were made on the test coupon of the in-house designed welding rig. The welding rig consisted of a 17.2 metre-long entrance pipe with an inner diameter of $114.7 \mathrm{~mm}$, resulting in an entrance distance of 150 diameters, connected to the weld test coupon, which also has an inner diameter of $114.7 \mathrm{~mm}$. In the rear end of the weld test coupon, an outlet nozzle was connected to maintain a pressure in the rig and move the outlet from the welding area. Fig 7.

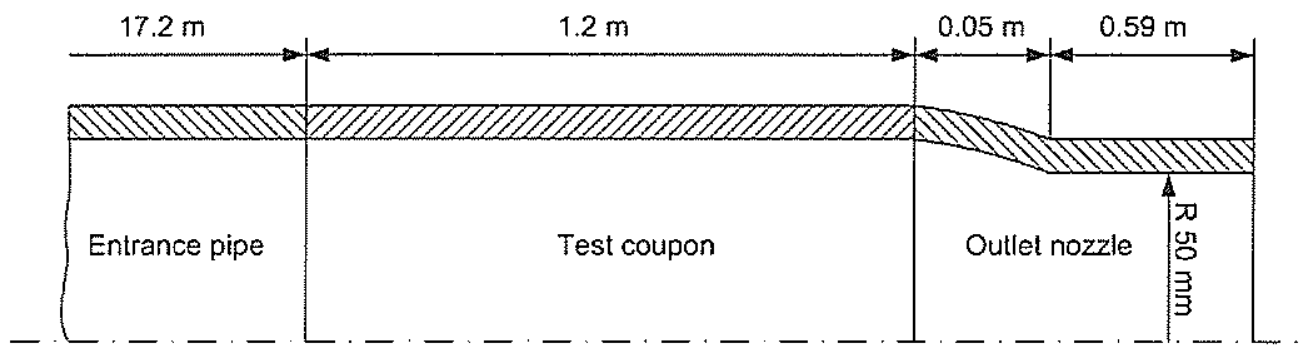

Fig 7. An illustration of the principal design of the in-service welding experiment rig. Illustration not to scale

Furthermore, four (4) longitudinal tapered slots were machined in the weld test coupon for the purpose of simulating a bevel joint preparation as well as giving the welder guiding support during the welding. Fig 8 .
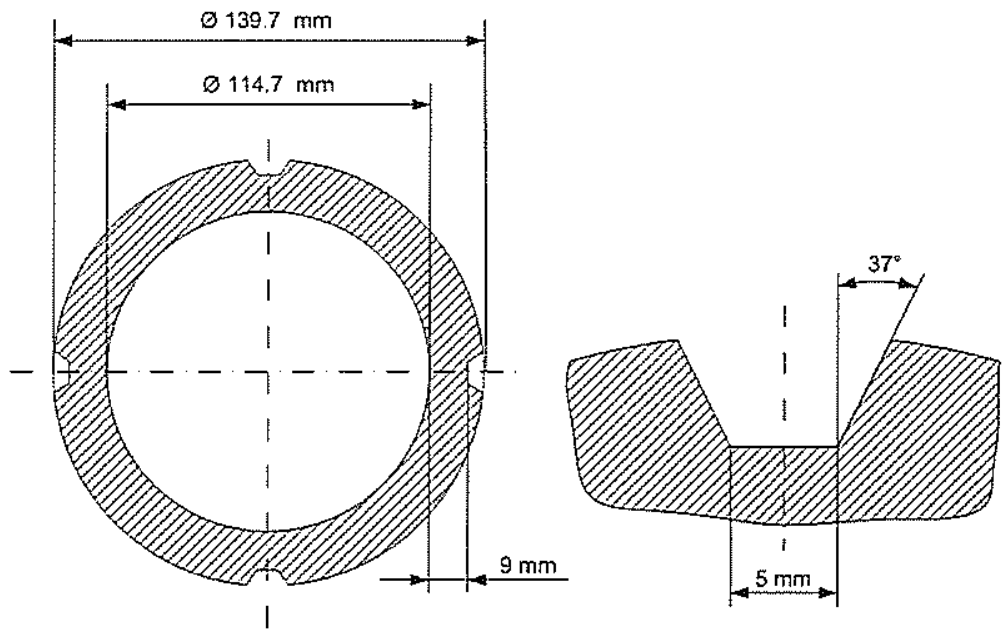

Fig 8. A cross-section view of the rig's weld test coupon, left, and the weld test coupon's groove, right. 
The welds were divided into four (4) groups A, B, C and D, where the purpose of Group A was to serve as a reference of 'normally produced welds', i.e. welding with the reverse side of the base material exposed to still air. The heat transfer coefficient, $\alpha_{f}$, of still air is about $10 \mathrm{~W} /\left(\mathrm{m}^{2}{ }^{\circ} \mathrm{C}\right)[30]$. During the wet part of the experiment the weld-rig outlet water temperature was measured at $0.1{ }^{\circ} \mathrm{C}$ and, as the reverse side of the test coupon is believed to have been exposed to a completely developed turbulent boundary layer of fresh water at a velocity of $3.45 \mathrm{~m} / \mathrm{s}( \pm 5 \%)$, it is believed that the heat transfer coefficient, $\alpha_{f}$, of group $\mathrm{B}, \mathrm{C}$ and $\mathrm{D}$ was about $8.6 \mathrm{~kW} /\left(\mathrm{m}^{2}{ }^{\circ} \mathrm{C}\right)$.

All welds were produced with single pass WPS in order to achieve a notable difference of maximum hardness in the HAZ. The welding process was selected Manual Metal Arc, MMA, $(\mathrm{DC}+)$. Consumables used during the experiment were ESAB OK 48.00 (7018) VacPac. The electrodes are vacuum-packed and stated by the manufacturer as having a hydrogen content of less than $5 \mathrm{ml} / 100 \mathrm{~g}$ weld metal deposit. Particulars of the consumables used are: $\varnothing 2.5 \mathrm{x}$ $350 \mathrm{~mm}$, Lot No. 9351341 ; $\varnothing 3.2 \times 450 \mathrm{~mm}$, Lot No. 2404331 and $\varnothing 4.0 \times 450 \mathrm{~mm}$, Lot No. 1356141. Particulars of the weld test coupon used are: DIN 17175 III (79) ST45.8; normalized condition $950^{\circ} \mathrm{C}$; Seamless steel pipe; Dimension $1200 \times \varnothing 139.7 \times 12.5 \mathrm{~mm}$; Hardness 150 HV; Manufacturer: Tuberie de St Saulve; Vallourec Industries; Réf: 26-97$274014 N^{\circ}$ VLR: JC6303/01; Heat No. 364439; Chemical Composition in weight \%, C 0.14; Si 0.17 ; Mn 0,95; P 0.014; S 0.004; Cr 0.07; Ni 0.04; W 0.005; Co 0.008; V 0.004; Cu 0.10; Al 0.037; Ti 0.002; Ce, Carbon Equivalent (IIW) 0.32 .

During the experiment, the welding process was continuously recorded by means of a Weldlogger $(8)$ type 500 Plus, sampling rate: $10 \mathrm{~Hz}$, Serial No. 301699 , manufactured by HKS Prozesstechnik GmbH, Germany. The weld metal's temperature in a single point of each weld was recorded by a type $\mathrm{K}$ thermocouple connected to the Weldlogger ${ }^{\circledR}$. The Thermocouples were harpooned down in the rear end of the melt pool, recording the temperature in a point just beneath the weld metal surface [31] [32]. Weld parameters recorded during the experiment and the calculated heat input, $Q_{w}$, calculated with equation (3) and the peak temperatures measured are listed in Table 2.

\begin{tabular}{|c|c|c|c|c|c|c|c|}
\hline Table No. 2 & $\begin{array}{c}\text { Electrode } \\
(\mathrm{mm})\end{array}$ & $\begin{array}{c}\mathrm{I} \\
(\mathrm{A})\end{array}$ & $\begin{array}{c}\mathrm{U} \\
(\mathrm{V})\end{array}$ & $\begin{array}{c}\mathrm{V}_{\mathrm{w}} \cdot 10^{-3} \\
(\mathrm{~m} / \mathrm{s})\end{array}$ & $\begin{array}{c}\mathrm{Q}_{\mathrm{w}} \cdot 10^{-6} \\
(\mathrm{~J} / \mathrm{m})\end{array}$ & $\begin{array}{c}\alpha_{f} \\
\mathrm{~W} /\left(\mathrm{m}^{2}{ }^{\circ} \mathrm{C}\right)\end{array}$ & $\begin{array}{c}\text { Peak temp } \\
\left({ }^{\circ} \mathrm{C}\right)\end{array}$ \\
\hline Weld & 2.5 & 108 & 23.7 & 3.344 & 0.574 & 10 & 698 \\
\hline A 2 & 3.2 & 145 & 23.9 & 3.480 & 0.747 & 10 & Failed \\
\hline A 3 & 4.0 & 204 & 24.9 & 4.488 & 0.849 & 10 & 1000 \\
\hline B 1 & 4.0 & 205 & 24.4 & 4.671 & 0.803 & $8.6 \cdot 10^{3}$ & 1000 \\
\hline B 2 & 4.0 & 204 & 24.7 & 4.944 & 0.764 & $8.6 \cdot 10^{3}$ & 1000 \\
\hline B 3 & 4.0 & 218 & 26.5 & 4.210 & 1.029 & $8.6 \cdot 10^{3}$ & 1000 \\
\hline C 1 & 3.2 & 149 & 24.2 & 3.668 & 0.737 & $8.6 \cdot 10^{3}$ & 869 \\
\hline C2 & 3.2 & 149 & 24.0 & 3.942 & 0.700 & $8.6 \cdot 10^{3}$ & 702 \\
\hline C 3 & 3.2 & 149 & 24.8 & 4.003 & 0.692 & $8.6 \cdot 10^{3}$ & 1000 \\
\hline D 1 & 2.5 & $\mathrm{I} 40$ & 28.7 & 4.403 & 0.684 & $8.6 \cdot 10^{3}$ & 667 \\
\hline D2 & 2.5 & 140 & 29.1 & 4.223 & 0.723 & $8.6 \cdot 10^{3}$ & 900 \\
\hline D3 & 2.5 & 143 & 29.4 & 4.087 & 0.771 & $8.6 \cdot 10^{3}$ & 1000 \\
\hline
\end{tabular}


The fact that the peak temperatures of all welds produced by $\varnothing 4.0 \mathrm{~mm}$ consumables are measured at $1000^{\circ} \mathrm{C}$ indicates that the low peak temperatures depend on a weld pool thermocouple mass ratio. If the mass of the thermocouple is comparatively large in relation to the mass of the weld pool, an instantaneous drop in temperature and subsequent solidification occurs when the thermocouple penetrates the weld pool. It cannot be excluded that some weld pools have been super-cooled by some hundred degrees $\left(100-200^{\circ} \mathrm{C}\right)$. However, the weld pool temperatures have, without any doubt, been about $1500^{\circ} \mathrm{C}$ as the steel has been in the state of a liquid fluid [33].

On the visual examination of the weld seams, it was noted that $\varnothing 2.5 \mathrm{~mm}$ consumables are not suitable for in-service welding. The assessment is based on the appearance of weld Nos A1, D1, D2 and D3. These welds showed unacceptable surface irregularities and distrustful colour.

The hardness of test coupon No. 2 in each group was tested with 30 indents, in a line perpendicular to the weld [34]. In order to verify that the values of test coupons No. 2 are representative for its group, a confirmatory check of the remaining coupons were carried out with 6 indents, in a line perpendicular to the weld [35]. The peak hardness, measured in the coarse grain zone of HAZ, agrees fairly well with the values indicated in the CCT-diagram of a similar material [36]. Hardness values measured on test coupon 2 of each group are listed in Table 3.

\begin{tabular}{|c|c|c|c|c|}
\hline & Coupon $\mathrm{A} 2$ & Coupon B2 & Coupon $\mathrm{C} 2$ & Counon D2 \\
\hline Weld metal & $238 \mathrm{HV}$ & $269 \mathrm{HV}$ & $273 \mathrm{HV}$ & $286 \mathrm{HV}$ \\
\hline Coarse grained zone & $250 \mathrm{HV}$ & $329 \mathrm{HV}$ & $346 \mathrm{HV}$ & $343 \mathrm{HV}$ \\
\hline
\end{tabular}

The analysis of the unaffected base material's microstructure indicates a banded microstructure dominated by ferrite and perlite. Fig 9 and 10 .

The analysis of the microstructure in the area of the fusion line on the wet-test coupons shows that the dominating microstructure in the coarse grain zones has a martensitic -bainitic structure, Fig $11,12,13$ and 14 [37] [38]. 


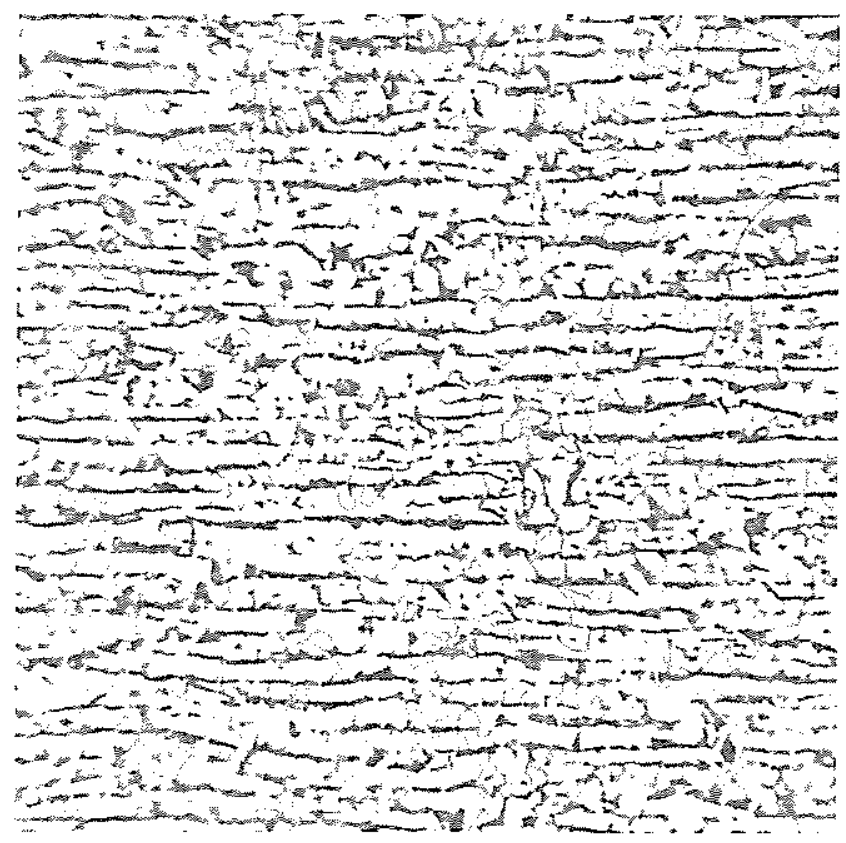

Fig 9. Microsection of unaffected base material test coupon No. B2. Light areas are ferrite grains, dark areas perlite. Magnification $75 \mathrm{x}$.

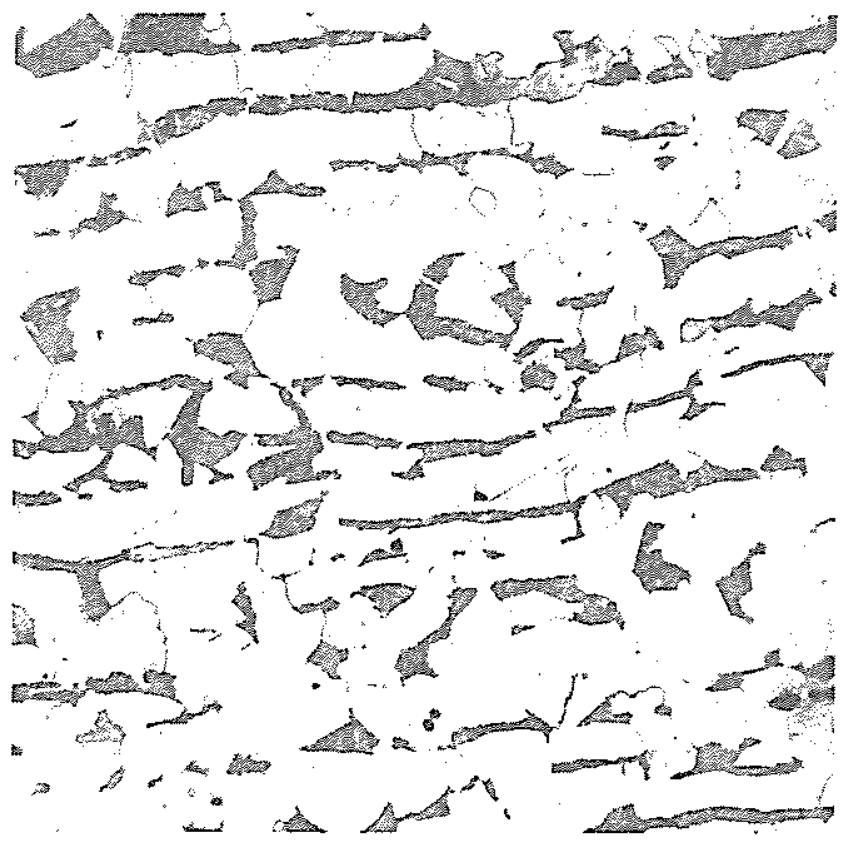

Fig 10. Microsection of unaffected base material test coupon No. B2. Light areas are ferrite grains, dark areas perlite. Magnification $290 \mathrm{x}$. 


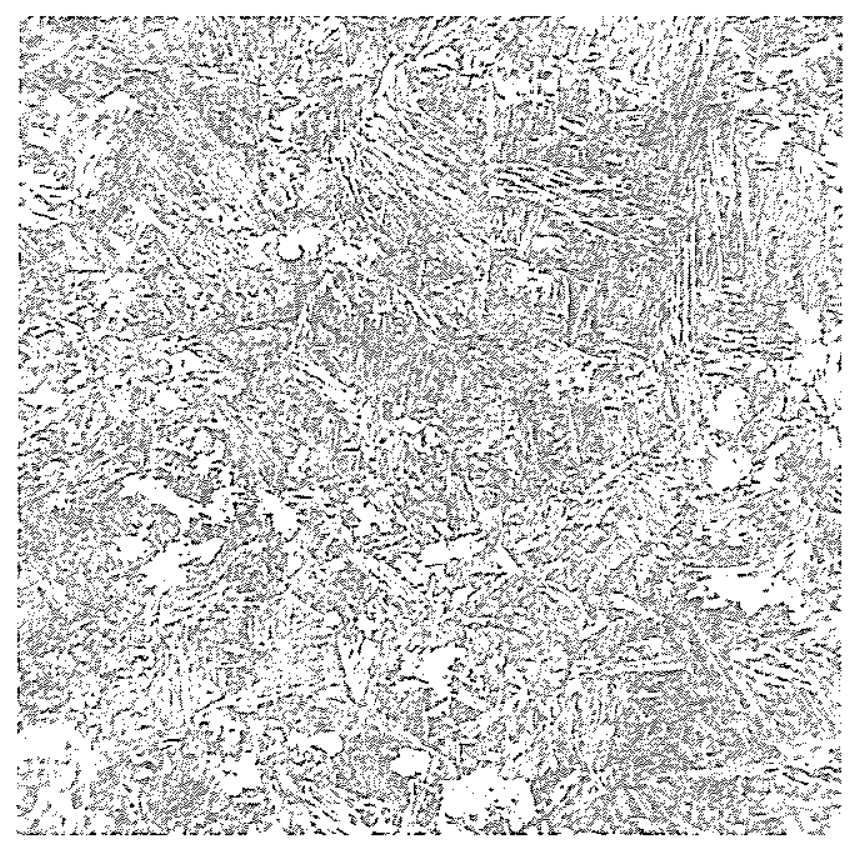

Fig 11. Microstructure of the coarse grain zone from test coupon No. A2. The dominating microstructure in the coarse grain zones has a martensitic - bainitic structure. Magnification $290 \mathrm{x}$.

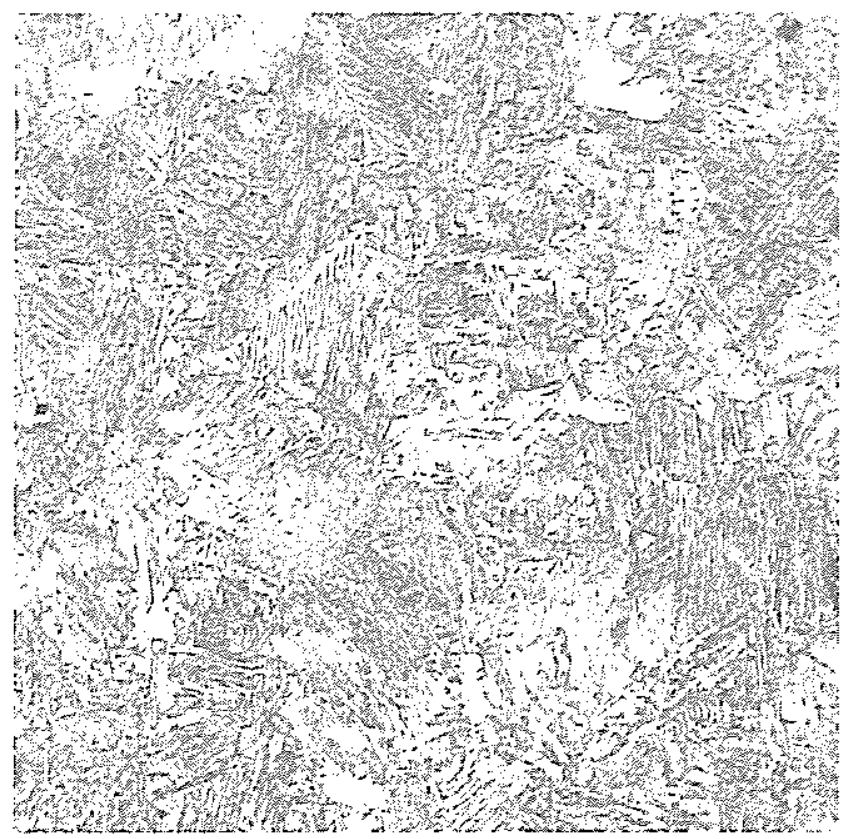

Fig 12. Microstructure of the coarse grain zone from test coupon No. B2. The dominating microstructure in the coarse grain zones has a martensitic - bainitic structure. Magnification $290 \mathrm{x}$. 


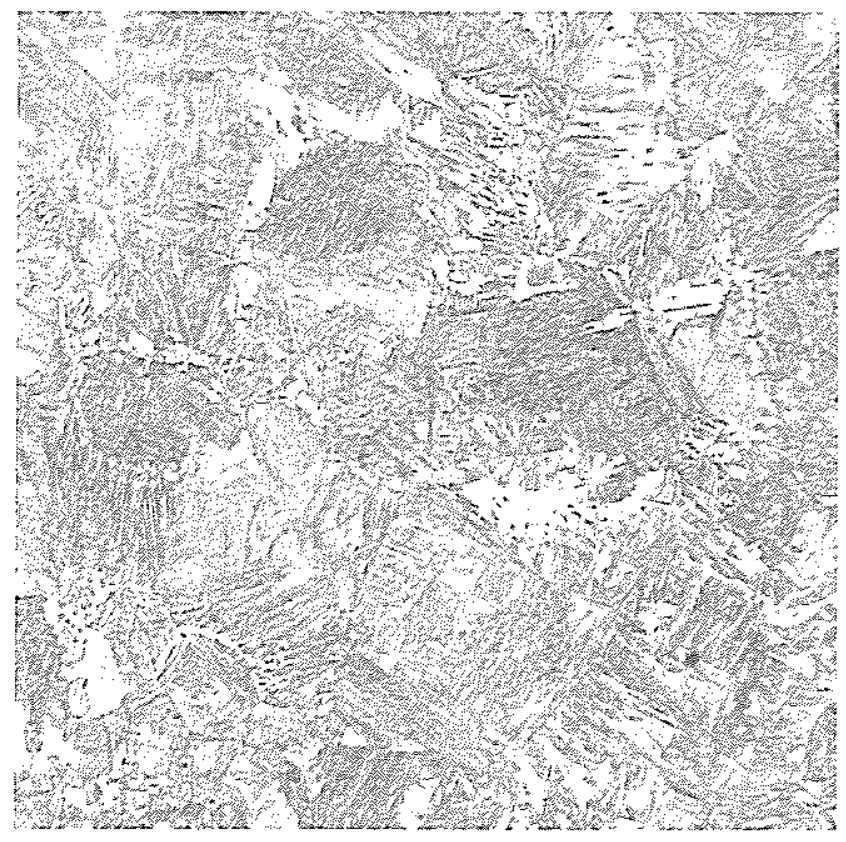

Fig 13. Microstructure of the coarse grain zone from test coupon No. $\mathrm{C} 2$. The dominating microstructure in the coarse grain zones has a martensitic - bainitic structure. Magnification $290 \mathrm{x}$.

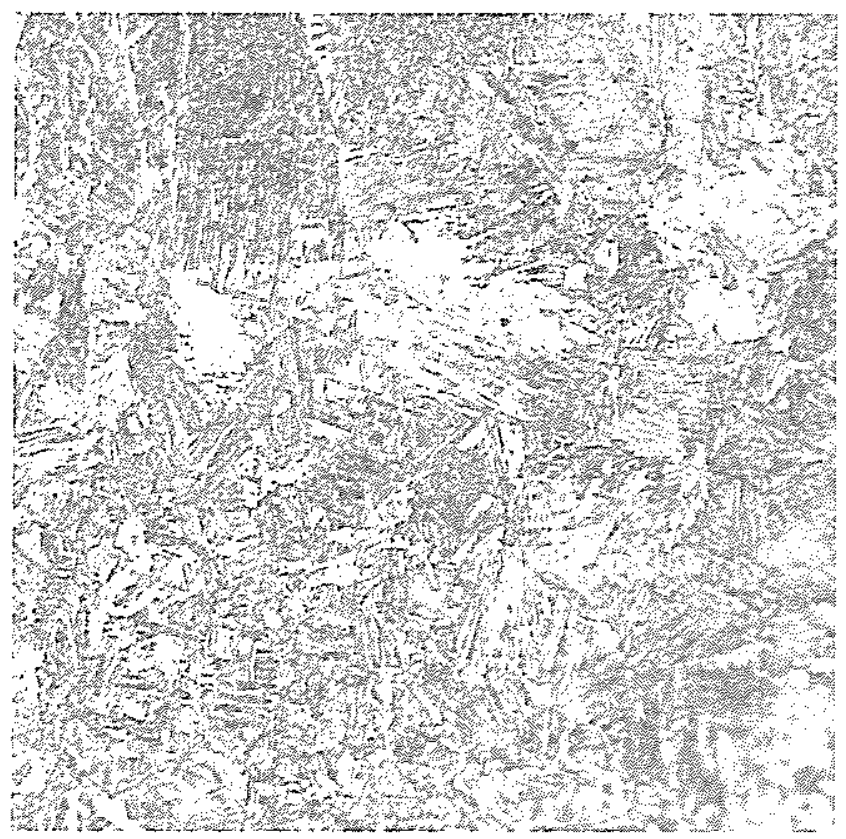

Fig 14. Microstructure of the coarse grain zone from test coupon No. D2. The dominating microstructure in the coarse grain zones has a martensitic - bainitic structure. Magnification $290 \mathrm{x}$. 


\subsection{Weld Repair of Shell Plates During Seagoing Operations, Paper A}

An algorithm to estimate the cooling rate of welding seams on the shell plating of a ship, below the waterline, while it is on voyage has been derived. The demand for this technique has arisen from the wish of ship operators to make it possible for the safe repair of ship structures without taking them out of operation. The strength of the shell plating after welding is determined by its metallurgic structure, which is dependent on the cooling rate, its chemical composition and the original grain size of the base material. The cooling rate for this type of welding seam depends on the velocity of the water flow, the distance from the bow, the thickness of the plate, and the heat from the heat input of the welding. The algorithm makes it possible to calculate the cooling rate for a base material affected by a forced flow of fluid by means of Rosenthal's equation and thus enabling suitable welding parameters to be determined.

As the welding parameters can be chosen to fit the specific repair to be made, it is now possible to determine the suitability of a welding procedure in advance. The algorithm is applicable when determining welding parameters at Hot-Tapping operations as well, where the base material is affected by a forced flow of fluid. A number of experiments have been performed and the results support the theoretical model. The research project continues with the aim of finding an algorithm to include the enhanced cooling rate due to the layer of boiling fluid on the back of the base material. A method to improve the measurements of the most important parameter in the algorithm has been developed and makes it possible to build up a quantitative database of typical values for various configurations.

Keywords: welding, in-service, heat transfer, seagoing operation, forced flow of fluid, boundary layer

\section{2 "An Experimental Rig for Verification of the Mechanical Properties of Welds produced at In-service Welding", Paper B}

The strength of a weld joint is determined by its geometry and its metallurgic structure, which is dependent on the cooling rate, its chemical composition and the original grain size of the base material. During in-service welding of structures affected by a forced flow of fluid on its reversed side the cooling rate depends on the fluid's boundary layer, the material's thickness and the heat input of the welding process. Currently, the calculation of the cooling rate during in-service welding is made by means of numerical methods such as the Finite Element Method, FEM. Through the introduction of an apparent thermal conductivity, $\mathrm{k}_{\mathrm{PL}}$, it possible to determine the cooling rate for specific welding parameters by means of Rosenthal's equation. This can be done with a standard pocket calculator.

An experimental rig for measurement of the heat transfer during the in-service welding of structures affected by a forced flow of fluid on its reversed side has been designed and built. The physical principles of welding on plates affected by a forced flow of fluid on their reverse side are the same as for welding on the circumference of a pipe containing a forced flow of fluid. In the rig, the required boundary layer is built up in a pipe system by means of a pump. As the flow and the temperature of the fluid can be controlled to simulate the specific heat transfer, it is now possible to verify the values of the apparent thermal conductivity, $\mathrm{k}_{\mathrm{PL}}$, that 
were calculated by means of FEM. A quantitative database will be filled with values of the apparent thermal conductivity, $\mathrm{k}_{\mathrm{PL}}$, for various configurations.

For the purpose of evaluation and qualification of in-service Welding Procedures Specifications, WPS, the sponsors of the research project use the experimental rig.

Keywords: welding, in-service, hot-tapping, heat transfer, experimental, forced flow of fluid, boundary layer, WPS, WPQR, WPAR

\section{3 "Heat Transfer Prediction of In-Service Welding In a Forced Flow of Fluid", Paper C}

An algorithm for heat transfer prediction of in-service welding operations in a forced flow of fluid is presented. The algorithm presented is derived from Rosenthal's 3D heat flow equation and boundary layer approximations. This has been possible by the introduction of an apparent thermal conductivity, $\mathrm{k}_{\mathrm{PL}}$, which is a function of the boundary layer's heat transfer coefficient, $\alpha_{f}$, and the base material's thickness, $\delta$. This implies that a weld cooling time, $\Delta \mathrm{t} \mathrm{T}_{1} / \mathrm{T}_{2}$, in a forced flow of fluid can now be calculated by an ordinary engineering calculator and thus enabling suitable welding parameters to be determined.

The magnitude of $\mathrm{k}_{\mathrm{PL}}\left(\alpha_{f}, \delta\right)$ has been established by regression analysis of results from a parametric Finite Element Analysis, FEA, series of a total number of 107 numerical simulations. Furthermore, the result of the regression analysis has been validated and verified by a welding experiment series accomplished on an in-house designed and constructed inservice welding rig. The principle design of the welding rig as well as its instrumentation, a PC based Data Acquisition system, is described. In addition, a method to measure the weld metals cooling time, $\Delta t T_{1} / T_{2}$, by means of thermocouple elements is described.

Finally, the algorithm presented in this study has been proved feasible for industrial inservice welding operations of fine-grained carbon and carbon-manganese steels with a maximum Carbon Equivalent (IIW), Ce, of 0.32 .

Keywords: TIG, FEA, FEM, DAQ, Dt 8/5, welding, heat transfer, boundary layer, data acquisition, in-service welding, forced flow of fluid, cooling time 


\section{$7 \quad$ Conclusions}

The research study has been successful as:

- It has been found that when welding is carried out on a plate with a thermal boundary layer on the opposite side the cooling rate is higher for the thinner plate. This is contrary to the experience of welding in calm air, where the experience is that the cooling rate increases with increase in thickness. Paper $\mathbf{A}$

- It has been proved that it is possible to weld, without preheating, on a shell plate below the water line of a ship in port. This can be done on all ship materials up to Grade EH 36 with some specific requirements. Paper A

- It has been found that weld joints produced with the reverse side of the base material cooled by still air have a lower maximum hardness in the coarse- grained zone compared to welds produced with its reverse side cooled by a flow of water. Paper B

- It has been found that the maximum hardness in the coarse-grained zone, can be controlled by means of the heat input, $Q_{w}$. Paper B

- Differences in the heat input, $\mathrm{Q}_{w}$, during manual welding has been measured. Paper B

- It has been found that $\varnothing 2.5 \mathrm{~mm}$ MMA consumables should be avoided during in-service welding as they give a to low heat input. Paper B

- The function of the apparent thermal conductivity, $\mathrm{k}_{\mathrm{PL}}$, has been approximated and validated, equation (12). Paper C

- The $\mathrm{k}_{\mathrm{PL}}$-function in combination with the 3D-2D heat-flow limit thickness, $\delta_{3 \mathrm{D}}$, equation (4), has made it possible to predict the weld cooling time, $\Delta t T_{1} / T_{2}$, during welding on base materials affected by a forced flow of fluid on its reversed side. Paper $\mathrm{C}$

- The in-house designed and built DAQ-system, "MUGIN", has proved to fulfil the service for which it is designed. Paper C

- The algorithm for prediction of in-service welding cooling times, $\Delta t T_{1} / T_{2}$, in a forced flow of fluid has been proved feasible for industrial use of fine-grained carbon and carbon-manganese steels with a maximum Carbon Equivalent (IIW), Ce, of 0.32. Paper C 


\section{$8 \quad$ Future Works}

From experiences gained during this study, I can recommend further studies in the following disciplines that are related to welding in a forced flow of fluid. My recommendations are to investigate the possibility of:

- Deriving the 3D heat-flow limit equation into the function of the apparent thermal conductivity, $\mathrm{kPL}$, and thereby improving the algorithm presented in this study.

- Using numerical simulations of the weld joint's thermal cycle, solid - liquid - solid, to facilitate the prediction of its mechanical properties

- Achieving heat removal from a weld joint by injection of a gas-forming substance in the weld's melt pool.

- Replacing the arc welding process by means of diffusion bonding during in-service welding in a forced flow of fluid.

\section{$9 \quad$ Acknowledgement}

First of all, I would like to thank my supervisor, Professor Anders Ulfvarson, for fruitful collaboration and all his professional guidance during the course of this work.

The author would also like to express his gratitude to the organizations that have supported this study with resources such as finance, qualified material, equipment and knowhow:

\section{ABS Pumps AB}

A $\mathrm{H}$ Lindfors stipendiefond

$B \& N$ Nordsjöfrakt $A B$

ESAB Sverige AB

Finnheat $\mathrm{AB}$
Hugo Heymans forskningsfond

Kvaerner Power AB

Nautiska föreningen i Göteborg

Preem Raffinaderi AB

SSAB Oxelösund $A B$

GE Panametrics AB

The author would also like to gratitude following individuals for their support to the completion of this research study:

Bo Fredriksson, Production Manager of Kvaerner Power AB.

Lic. Eng Olle Thomsson, retired Principal Surveyor to Lloyd's Register, Sweden.

Michael Persson, Senior Superintendent to Tarbit Shipping AB.

Furthermore, the author would also like to expres his gratitude to Chalmers University of Technology for all the knowledge and resources that have been made available, and especially Professors Göran Bark, Birger Karlsson, Kenneth Eriksson, Lars Larsson and Lennart Löfdahl and Lars-Erik Svensson, as well as Research Engineer Bengt Erichsen and all others who have made this study possible by offering their support and advice. 


\section{References}

[1] Stopford, M., 1996, "Maritime Economics", ISBN 0-415-08438-5, 412 pp, Routledge, London.

[2] Easterling, K., 1992, "Introduction To The Physical Metallurgy of Welding, $2^{\text {nd }}$ Ed.", ISBN 075060394 1, 270 pp, Butterworth-Heinemann, Oxford

[3] Bruce, W. A., Principle Research Engineer of Edinson Welding Institute, private communication

[4] Bruce, W. A., 2001, "Selecting an Appropriate Procedure for Welding Onto In-Service Pipelines", International Conference on Pipeline Repairs, Welding Technology Institute of Australia, Wollongong, Australia

[5] Belanger, R. J., and Patchett, B. M., 2000, "The Influence of Working Fluid Physical Properties on Weld Qualification for In-Service Pipelines", pp. 209s -214s, Supplement to the Welding, Journal August 2000, American Welding Society

[6] EEMUA, 1996, "Guide for Hot Tapping on Piping and other Equipment, Publication No. 185:1996", The Engineering Equipment and Materials Users Association, London

[7] Perry, P., and Green, D., 1984, "Perry's Chemical Engineers' Handbook", 6 ${ }^{\text {th }}$ Ed, MacGraw-Hill, Singapore

[8] Ullman, G., 1997, " The Mechanical Design Process, International Editions 1997", ISBN 0-07-065756, $340 \mathrm{pp}$, McGraw-Hill, Singapore

[9] Rosenthal, D., 1946, "The theory of moving sources of heat and its applications to metal treatments", Trans. ASME, 68, 849

[10] Rykalin, N. N., 1957, "Berechnung der Wärmevorgänge beim Schweissen, Verlag Technik, Berlin

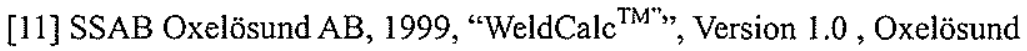

[12] Svensson, L.-E., 1994, "Control of microstructures and properties in steel arc welds", ISBN 0-8493-8221-1, 240 pp, CRC Press Inc., Boca Raton

[13] Lindström, P., and Ulfvarson, A., 2002, "Weld Repair of Shell Plates During Seagoing Operations", $21^{\text {st }}$ International Conference on Offshore Mechanics and Arctic Engineering, ASME

[14] Schlichting, H, 1979, "Boundary Layer Theory, $7^{\text {th }}$ English Edition", McGraw-Hill, New York

[15] Oosthuizen, P. H., and Naylor, D., 1999, "Introduction to Convective Heat Transfer Analysis", McGraw-Hill, New York

[16] Larsson, L., and Eliasson R., 2000, "Principles of yacht design", Adlard Coles Nautical, London

[17] Schlichting, H., and Gersten, K., 2000, "Boundary Layer Theory, $8^{\text {th }}$ Revised and Enlarged Edition", ISBN 3-540-66270-7, 799 pp, Springer, Berlin

[18] Eckert, E., and Drake, M., 1987, "Analysis of Heat and Mass Transfer", ISBN 0-89116553-3, 806 pp, Hemisphere Publishing Corporation, New York 
[19] Lindström, P., and Faraji, M., 2004, "Review and selection of a Finite Element Simulation Platform for Academic and Industrial Analyses of In-Service Welding Operations", $23^{\text {rd }}$ International Conference on Offshore Mechanics and Arctic Engineering, A.SME

[20] Snorri Sturulson, 1220, "Edda", Iceland

[21] EN 1011-2, 2001 " "Welding - Recommendations for welding of metallic materials - Part 2: Arc welding of ferritic steels", Swedish Standards Institute, Stockholm

[22] EN 1011-2/A1:2004, 2004, "Welding - Recommendations for welding of metallic materials - Part 2: Arc welding of ferritic steels", Swedish Standards Institute, Stockholm

[23] prEN ISO 15614, 2004, "Specification and qualification of welding procedures for metallic materials - Welding procedure test, Swedish Standards Institute, Stockholm

[24] Tusek, F., Markelj, J., Barbic, J., Jez, B., 2003, "Influence of type of weld joint on welding efficiency", Science and Technology of Welding and Joining, Volume 8, No. 3, Maney Publishing on behalf of $\mathrm{IOM}^{3}$, London

[25] Tuvander, M, Manager of ESAB AB's metal laboratory, Gothenburg, private communication

[26] Lindström, P., and Ulfvarson, A., 2003, "An Experimental Rig for Verification of the Mechanical Properties of Welds produced at In-service Welding", $22^{\text {nd }}$ International Conference on Offshore Mechanics and Arctic Engineering, ASME

[27] Bark, G., Professor in Marine Hydromechanics, Private communication, Chalmers University of Technology, Gothenburg, Sweden

[28] Dieter, G. E.; 1988, "Mechanical Metallurgy, SI Metric Ed", McGraw-Hill, Singapore

[29] DNV Rules for Ships, 2000, Oslo

[30] Mörstedt, S. E., and Hellsten, G., 1999, "Data och diagram", $7^{\text {th }}$ Ed, Liber, Stockholm

[31] Bruce, W. A., Principle Research Engineer of Edinson Welding Institute, private communication

[32] Svensson, L.-E., Professor at Chalmers University of Technology, private communication

[33] Lancaster, J. F., 1999, "Metallurgy of Welding, $6^{\text {th }}$ Ed", Abington Publishing, Cambridge

[34] Tuvander, M, Manager to the metall laboratory of ESAB Group, Gothenburg

[35] Kvaerner Pulping Welding and Material laboratory, Gothenburg, Supervised by Senior Metallurgist Eilersson, $\mathrm{T}$.

[36] DIN 17155 Stahl $19 \mathrm{Mn} \mathrm{5,} \mathrm{,1961,} \mathrm{"Atlas} \mathrm{zur} \mathrm{värmebehandlung} \mathrm{der} \mathrm{stähle“,} \mathrm{Band} \mathrm{1,}$ Verlag Sthaleisen M.B.H., Düsseldorf

[37] The Welding Institute, 1984, "Metallography of Welds in Carbon-Manganese Steels, Slide set number 7, Introductory notes", The Welding Institute, Cambridge

[38] The Welding Institute, 1983, "Metallography of Welds in Carbon-Manganese Steels, Wall chart, Reference C4-83", The Welding Institute, Cambridge 
